\title{
Исследование погрешности измерений компаратора УКМ-100 для поверки концевых мер длины
}

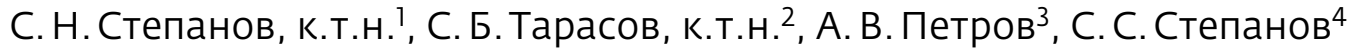

УДК 621.923

Проведены оценка погрешности и расчет неопределенности измерений на компараторе УКМ-100 для поверки концевых мер длины. Определены факторы, влияющие на неопределенность измерений, вычислены суммарная стандартная, а также расширенная неопределенность измерений. Перечислены основные технические характеристики компаратора УКМ-100. Описан процесс калибровки компаратора УКМ-100, установлены критерии, приведен протокол измерений 5 .
\end{abstract}

Ключевые слова: погрешность измерений, концевая мера длины, компаратор, неопределенность измерений, срединная длина, калибровка

The error was estimated and the measurement uncertainty was calculated on a UKM-100 comparator for checking end length measures. The factors influencing the measurement uncertainty are determined, the total standard as well as the extended measurement uncertainty are calculated. The main technical characteristics of the UKM-100 comparator are listed. The calibration process of the UKM-100 comparator is described, the criteria are established, the measurement protocol is given.

Keywords: measurement error, end length measure, comparator, measurement uncertainty, median length, calibration

Статья получена: 13.03.2020

Принята к публикации: 16.04.2020

В последнее время активно расширяется экономическая и научная интеграция международного сообщества. Важным элементом этого процесса является гармонизация стандартов и других нормативных документов, в том числе в области метрологии, цель которой - устранение барьеров в торговом, промышленном, научном и культурном сотрудничестве.

Следуя современным тенденциям, мы провели исследование точности отечественного компаратора

1 Санкт-Петербургский политехнический университет Петра Великого, оОо имц “Микро», stepanov56@mail.ru.

2 Санкт-Петербургский политехнический университет Петра Великого, ОоО имЦ "Микро".

3 Санкт-Петербургский политехнический университет Петра Великого, ОоО имЦ "Микро".

4 Санкт-Петербургский политехнический университет Петра Великого, оОо имЦ "Микро".

5 На правах рекламы. для поверки концевых мер длины УКМ-100 по международной методике Calibration of Gauge Block Comparators, применяемой всеми ведущими производителями компараторов для аттестации концевых мер длины.

Цель работы - оценка погрешности измерений и расчет неопределенности измерений на компараторе УКМ-100 для поверки концевых мер длины.

Для достижения поставленной цели необходимо решить следующие задачи:

- провести оценку измеряемой величины;

- определить факторы, влияющие на неопределенность измерений;

- вычислить суммарную стандартную неопределенность;

- вычислить расширенную неопределенность измерений.

Методика проведения эксперимента описывает процесс калибровки компаратора при измерении срединной длины и плоскопараллельности аттестуемой меры. 
Методика предназначена для компараторов для калибровки концевых мер длиной до 100 мм методом сравнения, контактным методом и только с применением двух преобразователей, контактирующих с мерой с противоположных сторон. Установка УКМ-100 полностью соответствует указанным условиям.

Компаратор УКМ-100 разработан на кафедре "Технология машиностроения" Санкт-Петербургского университета Петра Великого и предназначен для измерения срединной длины и определения отклонения от плоскопараллельности концевых мер длины 3 и 4 разрядов и рабочих мер длины 1-5 классов точности с номинальной длиной от 0,5 до 100 мм и применяется при их поверке. Принцип действия компаратора - индуктивный. Метод измерения сравнение с эталонной мерой.

Компаратор представляет собой компьютеризированное рабочее место поверителя (рис. 1), состоящее из лабораторного стола, в столешницу которого встроена гранитная плита. В плиту вмонтирована колонка ø80 мм с двумя кронштейнами - верхним и нижним. В кронштейны установлены индуктивные преобразователи (ИП). Нижний кронштейн крепится неподвижно на колонке, верхний перемещается по колонке с помощью микровинта вращением маховика. иП расположены соосно.

Таблица 1. Основные технические характеристики

\begin{tabular}{|c|c|}
\hline Характеристики & Значение \\
\hline $\begin{array}{l}\text { Диапазон номинальных значений } \\
\text { длин измеряемых концевых мер, мм }\end{array}$ & От 0,5 до 100 \\
\hline $\begin{array}{l}\text { Отклонение длины измеряемых } \\
\text { концевых мер от длины эталонных, } \\
\text { мкм, не более }\end{array}$ & \pm 12 \\
\hline Дискретность отсчета, мкм & 0,01 \\
\hline $\begin{array}{l}\text { Размах показаний при арретирова- } \\
\text { нии индуктивных преобразовате- } \\
\text { лей, мкм, не более }\end{array}$ & 0,03 \\
\hline $\begin{array}{l}\text { Предел допускаемой абсолютной } \\
\text { погрешности, мкм }\end{array}$ & $\pm 0,05$ \\
\hline $\begin{array}{l}\text { Измерительные усилия индуктивных } \\
\text { преобразователей, сН } \\
\text { верхнего } \\
\text { нижнего }\end{array}$ & $\begin{array}{r}60-100 \\
30-60\end{array}$ \\
\hline $\begin{array}{l}\text { Разность измерительных усилий } \\
\text { верхнего и нижнего преобразовате- } \\
\text { лей, сН, не менее }\end{array}$ & 30 \\
\hline
\end{tabular}

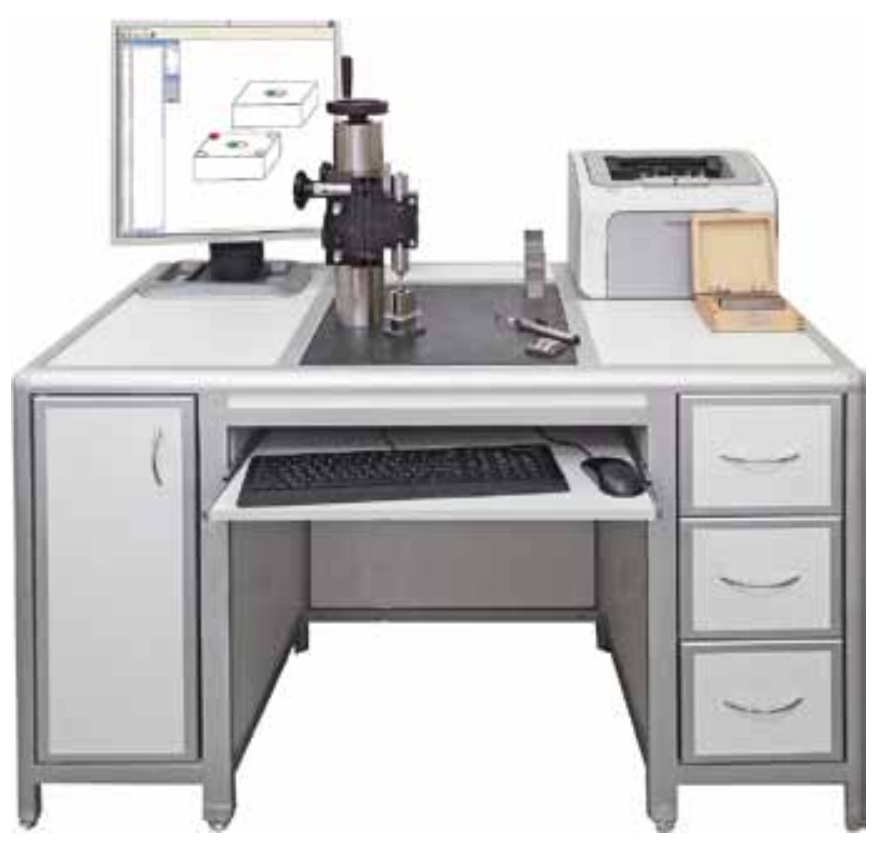

Puc. 1. Kомnapamop УКМ-100

Арретирование обоих преобразователей вакуумное и осуществляется автоматически. Эталонная и поверяемая меры располагаются в кассетах, которые перемещаются вручную оператором по траектории, определяемой шаблоном на кассете.

Основные технические характеристики представлены в табл. 1.

Программное обеспечение компаратора позволяет:

- автоматически арретировать индуктивные датчики;

- оценивать по размаху качество измерения в каждой поверяемой точке меры;

- подсказывать поверителю последовательность поверки;

- показывать на дисплее номинальный размер меры, схему поверяемых точек, настройку на номинальный размер, температуру окружающей среды, все значения поверяемой меры согласно стандартному протоколу;

- пересчитывать отклонения поверяемой меры с учетом поправок на эталонную;

- печатать протокол поверки (калибровки) и приложение к свидетельству;

- сохранять в памяти все действительные значения мер эталонных наборов до следующей аттестации.

Перед выполнением калибровки установка прошла полную подготовку и проверку на точность по методике поверки МП УКМ 100.01. В соответствии 
Таблица 2. Состав пар мер 1-го разряда

\begin{tabular}{ccc}
\hline Номер пары & \multicolumn{2}{c}{ Номинальная длина, мм } \\
\cline { 2 - 3 } & A & B \\
\hline 1 & 1,0 & 1,0 \\
\hdashline 2 & 1,0 & 1,01 \\
\hdashline 3 & 1,0 & 1,005 \\
\hdashline 4 & 10,0 & 10,0 \\
\hline 5 & 100,0 & 100,0 \\
\hline
\end{tabular}

с международной методикой для проведения калибровки были составлены следующие пары мер 1-го разряда (табл. 2).

Сравнение срединных длин мер. Меры укладывали по парам в гнезда кассеты и выполняли по пять сравнительных измерений срединных длин всех пяти пар. Затем серию измерений повторяли, после того как положение мер А и В в кассете меняли. Для каждой серии измерений были рассчитаны средние значения и стандартные отклонения (10 значений).

Измерение плоскопараллельности. Меру 1,01 мм укладывали в гнездо поверяемой меры и проводили серию из пяти измерений от срединной длины меры в углы A, B, D, E по схеме, показанной на рис. 2. Четыре измерительные серии были повторены, после поворота меры в гнезде кассеты на $180^{\circ}$ в горизонтальной плоскости. Были рассчитаны средние значения

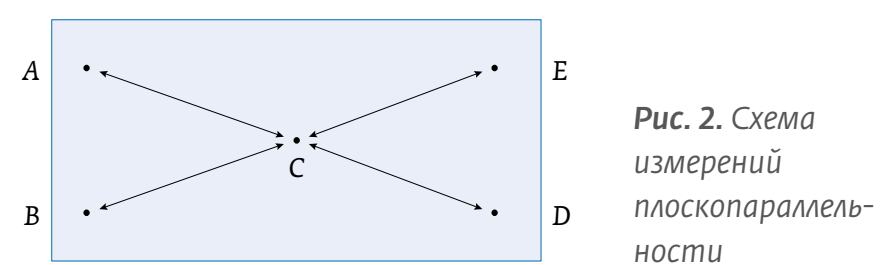

и стандартные отклонения для каждой из восьми серий.

Оценка результатов калибровки зависит от того, какие концевые меры по точности должны калиброваться с помощью компаратора. В методике рассмотрены критерии приемки из условия, что компаратор применяется для калибровки мер с расширенной неопределенностью измерений, равной $0,05+0,5 \mathrm{~L}$ при $k=2$, что соответствует концевым мерам 2-го разряда.

При этих условиях установлены следующие критерии:

- стандартные отклонения не должны превышать 0,015 мкм;

- максимальные отклонения средних значений и наибольших отклонений от плоскопараллельности от эталонных мер, указанных в протоколе поверки, не должны превышать 0,03 мкм.

Протокол измерений в соответствии с описан ${ }^{-}$ ной процедурой калибровки установки показан в табл. 3, 4.

Неопределенность измерений - параметр, связанный с результатом измерений и характеризующий рассеяние значений, которые могли бы быть обоснованно приписаны измеряемой величине.

Таблица 3. Погрешность компарации при измерении срединной дяины мер

\begin{tabular}{|c|c|c|c|c|c|}
\hline $\begin{array}{c}\text { Номинальный } \\
\text { размер мер, } \\
\text { мм }\end{array}$ & $\begin{array}{c}\text { Действительный } \\
\text { размер мер, } \\
\text { мм }\end{array}$ & $\begin{array}{c}\text { Разность } \\
\text { действительных } \\
\text { значений, } \\
\text { мкм }\end{array}$ & $\begin{array}{c}\text { Среднее } \\
\text { измеренное } \\
\text { значение, } \\
\text { мкм }\end{array}$ & $\begin{array}{c}\text { Среднее } \\
\text { квадратичное } \\
\text { отклонение, } \sigma \text {, } \\
\text { мкм }\end{array}$ & $\begin{array}{c}\text { Погреш- } \\
\text { ность, } \\
\text { мКм }\end{array}$ \\
\hline 1,0 & 1,00002 & \multirow{2}{*}{5,12} & \multirow{2}{*}{5,11} & \multirow{2}{*}{0,012} & \multirow{2}{*}{$-0,01$} \\
\hline 1,005 & 1,00514 & & & & \\
\hline 1,0 & 1,00002 & \multirow{2}{*}{10,01} & \multirow{2}{*}{10,02} & \multirow{2}{*}{0,014} & \multirow{2}{*}{0,01} \\
\hline 1,01 & 1,01003 & & & & \\
\hline 10,0 & 9,99996 & \multirow{2}{*}{0,03} & \multirow{2}{*}{0,04} & \multirow{2}{*}{0,011} & \multirow{2}{*}{0,01} \\
\hline 10,0 & פרפרפ,פ & & & & \\
\hline 50,0 & 49,99998 & \multirow[b]{2}{*}{0,14} & \multirow[b]{2}{*}{0,15} & \multirow[b]{2}{*}{0,013} & \multirow[b]{2}{*}{0,01} \\
\hline 50,0 & 49,99984 & & & & \\
\hline 100,0 & 100,00002 & \multirow{2}{*}{0,0} & \multirow{2}{*}{0,01} & \multirow{2}{*}{0,012} & \multirow{2}{*}{0,01} \\
\hline 100,0 & 100,00002 & & & & \\
\hline
\end{tabular}




\section{КЛЮЧЕВОЕ СОБЫТИЕ ОТРАСЛИ: в центре внимания, в центре Москвы}

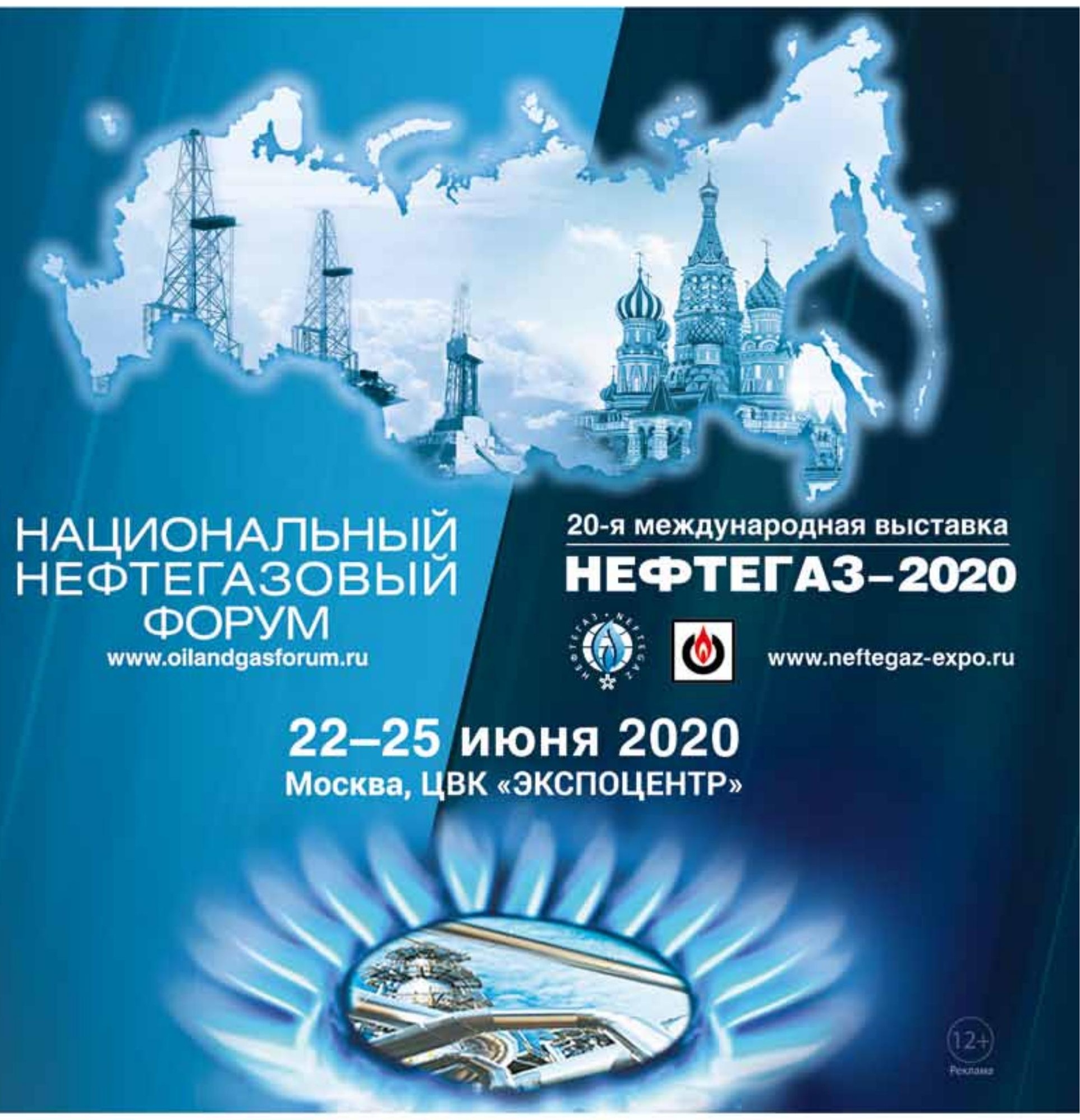

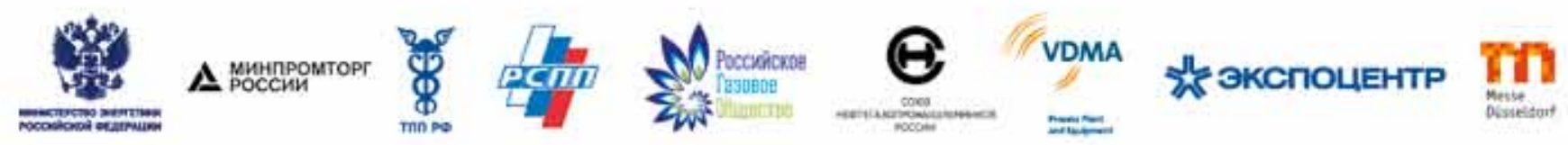


Таблица 4. Погрешность компарации при измерении плоскопараплельности

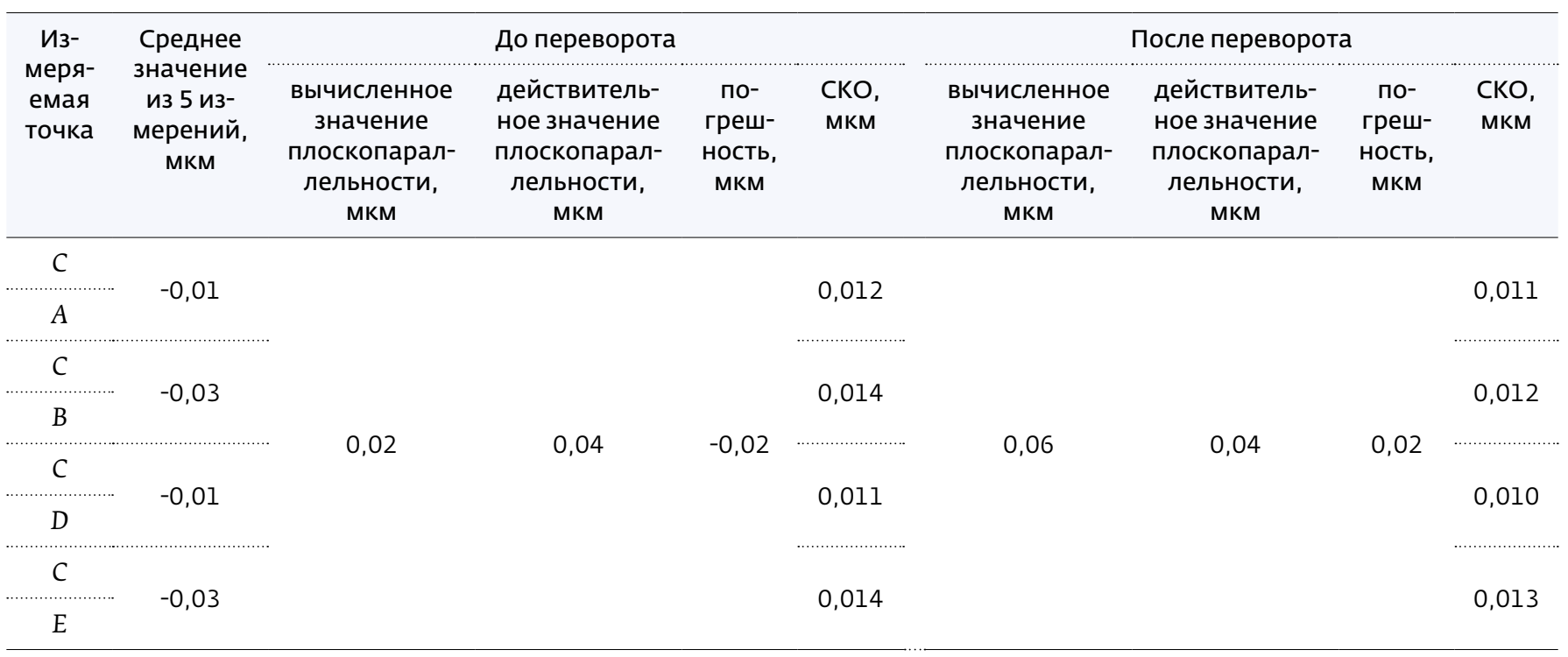

Таблица 5. Бюджет неопределенности

\begin{tabular}{|c|c|c|c|}
\hline Входные величины & $\begin{array}{c}\text { Стандартные } \\
\text { неопределенности } \\
\text { входных величин, } \\
\text { мкм }\end{array}$ & $\begin{array}{c}\text { Тип } \\
\text { неопределенности }\end{array}$ & $\begin{array}{c}\text { Вклад } \\
\text { неопределенности, } \\
\text { мкм }\end{array}$ \\
\hline $\begin{array}{l}\text { Среднее значение абсолютной } \\
\text { погрешности }\end{array}$ & 0,011 & A & 0,004 \\
\hline Дискретность УКМ-100 & 0,01 & $B$ & 0,003 \\
\hline $\begin{array}{l}\text { Точности оценки срединной дли- } \\
\text { ны и плоскопараллельности КМД } \\
\text { 1-го разряда }\end{array}$ & 0,01 & $B$ & 0,003 \\
\hline $\begin{array}{l}\text { Доверительная погрешность измере- } \\
\text { ния длины КМД 1-го разряда }\end{array}$ & 0,02 & B & 0,007 \\
\hline \multicolumn{3}{|c|}{ Суммарная стандартная неопределенность абсолютной погрешности $U_{c}$, мкм } & 0,009 \\
\hline \multicolumn{3}{|c|}{ Расширенная неопределенность абсолютной погрешности $U_{c}$ с вероятностью 0,95, мкм } & 0,018 \\
\hline
\end{tabular}

Расчет бюджета неопределенности выполнен согласно Национальному стандарту Российской Федерации ГОСТ Р 54500.3-2011/ Руководство ИСО/ МЭК 98-3:2008. Неопределенность измерения. Часть 3. Руководство по выражению неопределенности измерения (табл. 5).

\section{Выводы}

- Проведенные исследования показали, что компаратор УКМ-100 по своим точностным характеристикам, полученным на основании калибровки, соответствует компараторам для поверки концевых мер длины 2-го разряда;
- калибровка как метод оценки точностных возможностей эталонных приборов является более гибкой, чем применение поверочной схемы.

\section{Литература}

1. Любомудров С.А., Степанов С.Н., Тарасов С. Б. Метрологическое обеспечение производства. Учебник. - СПб: СПбПту, 2008.

2. Любомудров С. А., Степанов С.Н., Тарасов С. Б. Методы и средства измерения в машиностроении. Учеб. пособие. - СПб: СПбГПУ, 2011.

3. ГОСТ Р 54500.3-2011/ Руководство ИСО / МЭК 98-3:2008. Неопределенность измерения. Часть 3. Руководство по выражению неопределенности измерения.

4. Чуновкина А.Г. Погрешность измерения, неопределенность измерения и неопределенность измеряемой величины // Измерительная техника. 2000. № 7. С. 19-23. 


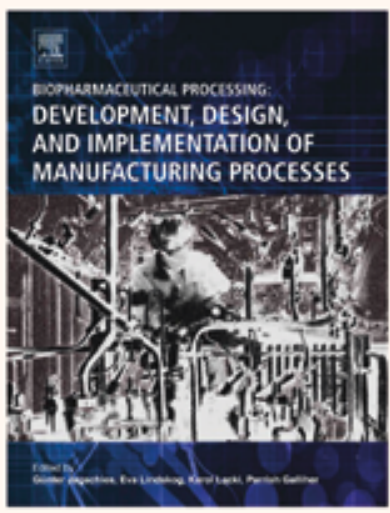

\section{БИОФАРМАЦЕВТИЧЕСКОЕ ПРОИЗВОДСТВО. \\ Разработка, проектирование и внедрение технологических процессов}

\section{Г. Ягшиш, Э. Линдског, К. Лаки, П. Галлихер}

Перевод с англ. (2018, Biopharmaceutical Processing. Development, Design, and Implementation of Manufacturing Processes)

Под ред. Ишмухаметова А.А., Пятигорской Н.В.

2020 г., 2 тома, ок. 1500 с., цв.ил., табл., тв. пер., 210×270 мм

До 1 апреля 2020 г. вы можете подписаться на издание по специальной цене. Подписная цена -8000 р., цена после выхода -9500 р.

Выход книги - 3 квартал 2020 г.

В уникальном издании рассматривается весь спектр биотехнологий от создания линии клеток до получения лекарственной субстанции. Описанные в ней методы и стратегии представляют собой сведения, необходимые для всех исследователей, инженеров-технологов и специалистов, занятых в области производства биофармацевтических препаратов и вакцин.

Целостность биопроцесса в конечном итоге определяет качество биотерапевтического препарата, и в настоящей книге подробно рассматриваются все стадии производства, включая все технологии, связанные с очисткой целевого продукта и процессом культивирования. Особое внимание уделено обширным экономическим аспектам с рекомендациями по уменьшению затрат и повышению эффективности. Приведены многочисленные данные, расчеты и руководства, что позволяет использовать издание в качестве незаменимого инструмента для исследователей и управленческих работников биофармацевтической отрасли. В специальных главах рассмотрены аналитические методы и вопросы регулирования.

Издание не имеет российских аналогов и адресовано специалистам биофармацевтических производств - исследователям, биотехнологам, биоинженерам, разработчикам вакцин, био-субстанций и препаратов, руководителям и менеджерам, отвечающим за организацию, безопасность и контроль качества биофармацевтических производств, органам регулирования и надзора, преподавателям и студентам профильного направления.

\section{ИСО/МЭК $17025: 2017$}

Практические рекомендации по применению. 2-е издание, исправленное и дополненное

И. В. Болдырев

2020 r., 128 c., $165 \times 235$ мм

\section{Цена: 1300 р.}

Введённый действие в сентябре 2019 года межгосударственный стандарт ГОСТ ISO/IEC 17025-2019 по сравнению с предыдущей редакцией от 2009 года претерпел существенные изменения, они коснулись структуры, терминологии, требований к ресурсам, процессам и системе менеджмента. Особое внимание уделено вопросам метрологической прослеживаемости результатов. Введены требования к «управлению рисками и возможностями». Изменена концепция установления требований к лабораториям.

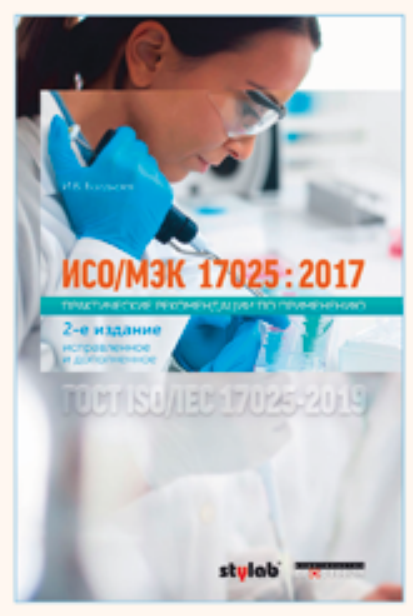
Они стали менее конкретными, что требует от лабораторий более вдумчивой и работы по организации своих систем менеджмента.

Комментарии и практические рекомендации направлены на то, чтобы облегчить лабораториям переход на новую редакцию ГОСТ ISO/IEC 17025.

Книга предназначена для широкого круга специалистов испытательных и калибровочных лабораторий, специалистов по качеству, экспертов по аккредитации. 